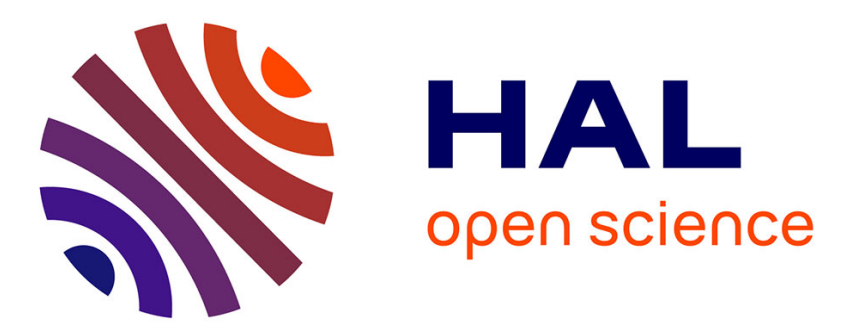

\title{
Identification of Factors During the Introduction and Implementation of PLM Methods and Systems in an Industrial Context
}

\author{
Vahid Salehi, Chris Mcmahon
}

\section{- To cite this version:}

Vahid Salehi, Chris Mcmahon. Identification of Factors During the Introduction and Implementation of PLM Methods and Systems in an Industrial Context. 12th IFIP International Conference on Product Lifecycle Management (PLM), Oct 2015, Doha, Qatar. pp.376-383, 10.1007/978-3-31933111-9_35. hal-01377463

\section{HAL Id: hal-01377463 \\ https://inria.hal.science/hal-01377463}

Submitted on 7 Oct 2016

HAL is a multi-disciplinary open access archive for the deposit and dissemination of scientific research documents, whether they are published or not. The documents may come from teaching and research institutions in France or abroad, or from public or private research centers.
L'archive ouverte pluridisciplinaire HAL, est destinée au dépôt et à la diffusion de documents scientifiques de niveau recherche, publiés ou non, émanant des établissements d'enseignement et de recherche français ou étrangers, des laboratoires publics ou privés. 


\title{
Identification of factors during the introduction and implementation of PLM methods and systems in an industrial context
}

\author{
Vahid Salehi' ${ }^{1}$, Chris McMahon ${ }^{2}$, \\ ${ }^{1}$ Munich University of Applied Sciences, Munich, Germany \\ Salehi-d@hm.edu \\ ${ }^{2}$ University of Bristol, Bristol, UK \\ chris.momahon@bristol.ac.uk
}

\begin{abstract}
The automotive engineering process is characterized by a long and complex design activity which starts with requirements formulation and the first sketches in the preliminary de-sign phase and extends to the final detailed and physical models. Every design phase includes different process steps and tasks which are closely interconnected with each other. The different design stages demand Product Life Cycle (PLM) systems, which are able to handle the different kinds of design and manufacturing information. Currently the implementation of PLM systems in an industrial context is a huge challenge. The reason therefore is that the companies are not only faced with the technical issues of such systems but also with the organization aspects like the "human factor". Furthermore the companies are faced with problems, which are not directly linked to the functionalities of PLM systems but rather to the integration or implementation phase of such systems in companies. The key research question in this case is: what are the important factors, which influence the integration and implementation of PLM systems. The following paper will try to identify these factors by means of action research in the automotive industry. This paper reports the first stages from a research programme into the implementation factors of PLM systems adopting the design research methodology (DRM) according to Blessing. The focus of this paper is to define method and systems implementation approaches and present the results of the descriptive study which has been accomplished to identify the challenges, problems and weaknesses involved in the implementation of PLM systems.
\end{abstract}

Keywords: Product Life Cycle Management, success factors PLM, PLM implementation, PLM integration

\section{Introduction}

This section will define the important aspects which should be considered during the implementation of PLM systems in an industrial context. A series of research papers and works was involved with the implementation and integration of systematic design methods and Tools [STREICH, 1997], [BESKOW, 1998], [TAMIMI, 1998], [STETTER, 2000]. In all of the works, it was mentioned that during the 
implementation of PLM system and its methods the change management process of the participants should be considered. According to Abramovici [ABRAM, 2012] the implementation of PLM projects are not working very well. Only $18 \%$ of the planned PLM project are successful and implemented in the planned period of time and costs. Furthermore $40 \%$ of the PLM project has been stopped. The other parts of the PLM implementation has been finishes under enormous costs and further efforts.

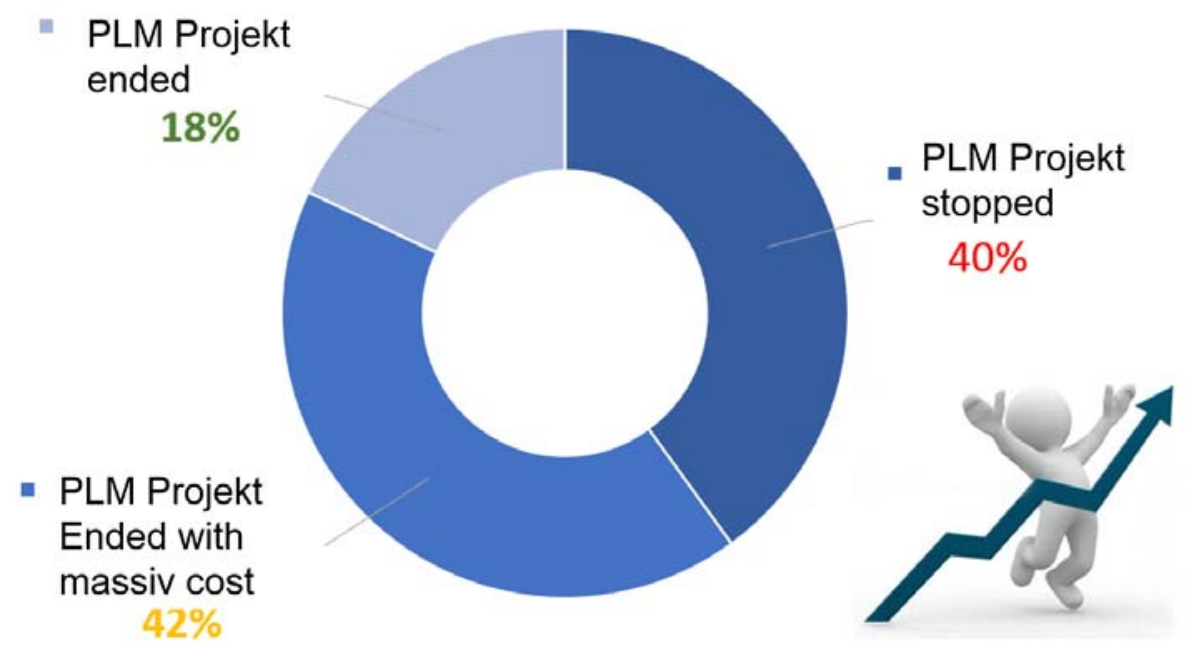

Fig. 1. Implementation of PLM projects and systems [ABRAMOVICI, 2012]

Furthermore Streich describes [STREICH, 1997], that the starting point is the question if the competence of the actors who are responsible for the process of the change management can be clearly perceived. Besides, the following important dimensions (competence fields) have to be considered in particular:

- $\quad$ Ability to do something, change of ability

- Willingness to do something, change of readiness

- $\quad$ Possibility to do something, change possibility

In a well-balanced mix of these three competence fields the perceived ability in different situations can be raised [STREICH, 1997]. The basis of the action shows an innovative and changing plan which questions the established approach at the procedural and behavioural levels [STREICH, 1997]. New plans of change management require, apart from new contents, new methods and behaviour patterns. This "change management" shows two dimensions: the perceived competence and the period of time. The phases shown within the graph (from the shock up to integration) differ between people. But for effective learning processes (in this case the integration of new PLM Systems and Tools) the different stages have to pass quickly [STREICH, 1997]. The reason for consideration of the change management graph is that the implementation of a new method can also be seen as a "changing" of procedures and methods of different users. This is a very important aspect during the implementation and changing of new approaches. There are different procedures of implementing new design methods. According to Stetter [STETTER, 2000] activities that represent the 
adoption of new Tools, Systems and methods are the driving force of design methods. This means that one of the most important issues is the association and connection of the users in the implementation process. This process comprises the introduction, anchoring and the improvement of the new Systems. Several significant aspects of the implementation itself have to be taken into consideration to guarantee successful method implementation [STETTER, 2000]. Basically, the performance of new systems demands the accomplishment of an implementation strategy and the monitoring and the adaptation of the selected methods. Another very important point is to prevent users from developing a "resistance" to the intended change in of design process. For avoiding such "resistances" the author used the resistance pyramid of method implementation created by Beskow [BESKOW, 1998], which describes characteristic patterns of "resistance" demonstrated by workers during the implementation of methods. The resistance pyramid of Beskow [BESKOW, 1998] includes three different steps and levels. These levels are named as "not knowing", "not able" and "not willing". According to Tamimi [TAMIMI, 1998] changing users" "resistance" is one of the key issues and also very important for the implementation of new methods. He also defined strategies of how to counter people's resistance. The levels 'not knowing' and 'not able' can be attacked by means of teaching the new method, training the new method and coaching the users during the application of the new method [TAMIMI, 1998]. The best way to avoid the highest level of the resistance 'not willing' is to win such users' support for the method development, which means to integrate users into the implementation process. Now the next section of the paper will define the general methods of systems and method implementation approaches.

\section{General method-Implementation approaches}

The implementation of methods, systems and the factors which should be considered has been addressed by a number of studies [RITZEN, 1999; BESKOW, 1998; PAWAR 1997]. It is quite important to create a plan for determination of tasks and actions required to realize the method implementation [USHER, 1996]. According to Berndes [BERNDES, 1998] "the starting point of the method implementation is the planning of activities which contains the course of action, like the sequence and intensity in which certain activities are performed, the persons who perform them, and what resources will be available". Furthermore the planning of a method and system implementation process can be compared with the planning of a product development process. A large number of methods for planning are presented in the literature. From the viewpoint of planning, there is not much difference between a method implementation process and other determined processes, for example, product development. According to Lindemann [LINDEMANN, 1992] the choice of the planning system to apply should therefore be based on the capabilities and needs of the respective company. Furthermore it is important to remember that the systems need to be simple in order to remain trans-parent for the participants. According to Pinosz [PINOSZ, 1997] there are three different introduction strategies of methods and systems which are: 
- All-at-once: a method can be introduced by changing the whole system overnight.

- Pilot application: a method can be applied first in a pilot application of limited scope and then the scope can be expanded if the method has been proven to be useful and its faults have been corrected.

- Gradual approach: selected aspects, for example, rather simple accompanying tools of a method can be applied first, for ex-ample, in a particular department, and the other aspects can be introduced later - in a stepwise procedure - if the selected aspects were accepted by the users.

The first approach which is the 'all-at-once' approach will usually be too risky since methods and tools cannot be tested in advance under realistic conditions. Pinosz [PINOSZ, 1997] stated that if a method does not offer the full required functionality, it will quickly become a burden. Therefore, a rigorous testing phase of the developed PLM system was planned and expected. This aspect can also be captured from different literature and publications [DANNER/RESKE, 1999], [WEBER, 1999], [LETTICE, 1998], [SELLGREN/HAKELIUS 1996]. Related to the introduction of the developed PLM system the "pilot application" approach was the most suitable. By means of this approach it was possible:

- To verify the realization of the major objectives. That means to clarify the possible application times and also the PLM design examples which should be applied by the PLM users.

- To enhance the qualification of the employees by means of 'training on the job'. It was possible to observe that for PLM users it is more comfortable to apply the new learned method on their daily task.

- $\quad$ To provide PLM users and other participants like CAE and CAM engineers in the rest of the organization with real demonstrations.

- To intensively explore and highlight the needs of the PLM users.

- To assist the setting of realistic schedules.

The target of a "pilot project" was a precondition to be able to in-form all the PLM users and the design process participants like CAE and CAM engineers in detail. The pilot project for the introduction and implementation of the developed PLM system was planned for eight months. According to Usher [USHER, 1996] the main purposes of the pilot application are:

- A project should be selected that is large enough to include a good sampling of typical functions, but not so large that the success of the project is jeopardised.

- A project should be selected that will require resource commitment in terms of cost, time, and personnel without over-extending these resources.

- The product to be developed in the project should exhibit problems in terms of time, cost or quality in order to increase the likelihood of improvements.

- It has to be understood that this project is to be used as a training ground for management and team members. 
The integration of a "gradual approach" was considered not to be suitable. The most important reason for this was that the managers in the departments were waiting for already created and finished results at a time when even the collection of the data in the analysis of the product development system was not completed. Furthermore before starting to integrate the PLM system it was very interesting to get further information about the experiences of the PLM users with method implementation. From the viewpoint of the author this aspect is one of the important ones because by means of getting information about users' experiences it was possible to create a plan of how to tackle possible challenges during the PLM system implementation phase. In addition it was possible to create a fitted and suited introduction and implementation plan for the participants.

\section{$3 \quad$ Identified lacks during the PLM system implementation}

Another aspect was that you can not to make the same "mistakes" which have been done in the past during the implementation of methods in the PLM departments. For getting information about PLM users' experiences with method integration processes a questionnaire was designed to collect the problems and challenges of the PLM user during the implementation of a methodology. The most important results and problems of the users during the implementation of methods are presented here:

- Lack of involvement of the PLM users about the planned activities; $80 \%$ of the respondents mentioned that during the method planning and implementation process they are not sufficiently involved in activities which are necessary to implement the methods. Furthermore they also mentioned that managers tend to plan all the activities without any consideration of their needs and requirements. The PLM users also mentioned that they are willing to learn and apply methods which help them to work in a better way but a "top down" approach of integration of methods by managers leads to a certain degree of frustration for the users.

- Lack of support for PLM users during the application of methods; $87 \%$ of the respondents mentioned that in most of the cases there is a lack of support during the learning and application phase of new methods. Therefore it is quite important that during the initial phase of the method integration PLM coaches and external support are available for the designers. Furthermore the PLM users also stated that the PLM coaches and support people should be located in the same area as the PLM users. In this case it is ensured that in case of possible questions and problems during the learning and implementation process of the developed methods problems and difficulties can be tackled faster and immediately. The users also feel secure that in case of a problem someone is there who is able to help them. 
- Lack of the targets of the planned activities and the method; $78 \%$ of the respondents stated that in most of the cases the target of the activities and new methods are not clear and well explained. That means that there is less information about why the PLM users should learn a method. In case of the integration of the developed PLM system by means of the presentation of the results from the Descriptive Study I (in which all the users were involved) it was possible to show the weaknesses and challenges of the created PLM parts and assemblies. Furthermore by means of investigation of existing PLM parts it was possible to demonstrate the possible challenges and improvements during the modelling process.

- Lack of time resources which are necessary to implement the method. $93 \%$ of the PLM users mentioned that during the implementation of methods the time boundaries are not considered. That means that the time which is selected to implement the method is in most of the cases not suitable. The users also mentioned that if the people who are responsible for the integration of methods would ask and involve them in choosing possible time slots it would be more comfortable for the users to plan the implementation in their daily tasks. Related to PLM users this aspect was one of the important ones because in the design process there are several deadlines which are important for the users. For example there is a deadline about the release process of the created PLM parts and assemblies. At this time it was not very suitable and recommendable to implement the developed PLM method.

- Lack of having voice about possible changes and improvements of methods. Many of the users mentioned that it is very helpful if they would have the possibility to give a statement about possible improvements and changes of the methods. That means that in most of the case it their ideas about improvements are not sufficiently considered.

- Lack of communication about the planned activities. The achievements and the next steps and activities during the method implementation phase should be communicated to all the participants. Furthermore an "open" communication about problems helps to get more inputs about the weaknesses of methods which can be used for further improvements.

- Lack of financial resources which are necessary to implement the method. This aspect is more related to the management level. The users mentioned that in the initial phases of the method implementation there is a certain support necessary and in most of the cases there is no money planned to support the users. Most of the users have to learn methods beside their daily work and the time is missing to learn these approaches without any support. 


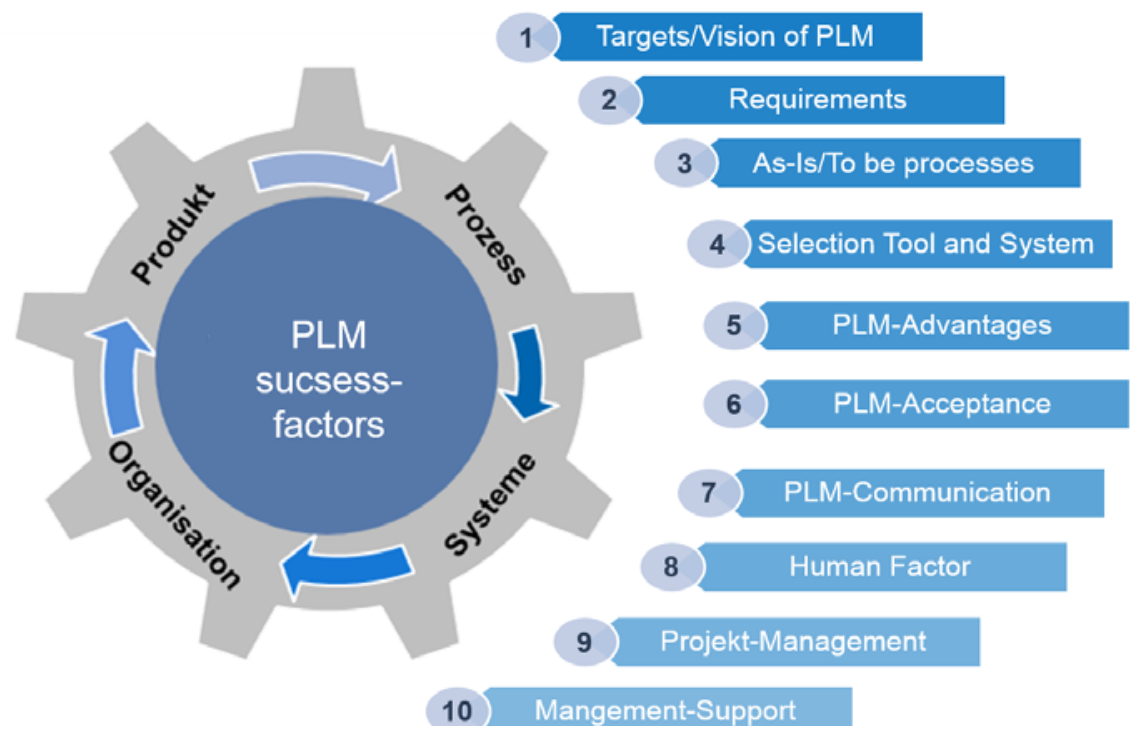

Fig. 2. Important factors, which influences the implementation of PLM systems

\section{Conclusion}

This chapter has presented issues in the implementation of PLM systems and approachs. Based on a questionnaire and the results of the literature survey the chapter has identified challenges and problems which have been considered during the implementation phase of PLM methods. It can also be concluded that a strong involvement of the PLM users during the planning and application of the developed PLM approach is one of the key issues which should be considered. The involvement of the PLM users in the improvements and development of the PLM approach leads to a very effective working and planning of the activities related to the approach. It can be ensured that by means of PLM users support there is a certain "commitment" of the de-signers about the planned activities available.

1. DANNER S., RESKE M., 1999; Systematic Design in Practice: Target Finding for Product and Process. In: Lindemann, U.; Birkhofer, H.; Meerkamm, H.; Vajna, S. (Eds.): Proceedings of the 12th International Conference on Engineering Design. Garching: TU München, pp. 233-236, 1999.

2. STREICH B., 2007; Change Management I - Lernen lernen Dozent: Prof. Dr. Thomas Bartscher Institut für Personal- und Unternehmensmanagement. page 1-13, 2007.

3. BESKOW C., JOHANSSON J., NORELL M., 1999; Changing the Product Development Process: a Study of QFD Implementations in Swedish Industry., Research report. Stockholm: Royal Institute of Technology, 1998. 
4. STETTER R., 2000; Method Implementation in Integrated Product Development, PhD Thesis an der Technischen Universität München, 2000.

5. TAMIMI, N., SEBASTIANELLI, R., 1998; The Barriers to Total Quality Management. Quality Progress, June 1998, page 60-72, 1998.

6. RITZÉN S.; BESKOW C.; NORELL M.: Continuous Improvement of the Product Development Process. In: Lindemann, U.; Birkhofer, H.; Meerkamm, H.; Vajna, S. (Eds.): Proceedings of the 12th International Conference on Engineering Design. Garching: TU München 1999.

7. LINDEMANN U., 1999; Benchmarking von Produktentwicklungsprozessen. In: Wildemann, H. (Ed.): Produktklinik. Wertgestaltung von Produkten und Prozessen. Methoden und Fallbeispiele. München: TCW Transfer-Centrum, pp. 112-135, 1999

8. PIKOSZ P.; MALMSTRÖM J.; MALMQVIST J., 1997: Strategies for Introducing PDM Systems in Engineering Companies. In: Proceedings of CE'97 Rochester 1997.

9. LETTICE F., EVANS S., SMART P., 1998; Understanding the Concurrent Engineering Implementation Process - A Study Using Focus Groups. In: Duffy, A. (Ed.) The Design Productivity Debate. Springer: London, pp. 187- 202, 1998.

10. WEBER C., 2007; A New Approach to Modelling Products and Product Development Processes: "Characteristics-Properties Modelling" (CPM), Leading to A New Methodical Concept to Develop Products: "Property-Driven Development/Design" (PDD) Saarland University - Universität des Saarlandes, Engineering Design, 2007

11. USHER J. 1996; Implementing Concurrent Engineering in Small Manufacturing Enterprises. Engineering Management Journal, Vol. 8, No. 1, March 1996, page 3343, 1996. 